\title{
In situ curing and bonding of epoxy prepregs in epoxy thermoset injection molding
}

\author{
Tim Deringer ${ }^{1} \cdot$ Dietmar Drummer $^{1}$ \\ Received: 19 February 2021 / Accepted: 2 August 2021 / Published online: 14 August 2021 \\ (C) The Author(s) 2021
}

\begin{abstract}
In this study, epoxy molding compounds are combined with fast-curing epoxy prepregs in thermoset injection molding using a new integrative process. The combination is carried out under the varied parameters of mold temperatures and curing times, which are dominant factors in thermoset processing. The focus of the investigations is the bond strength in the interface resulting from these parameters, as the interface is known as the weak point of hybrid components. To identify causes for possible increases and decreases of the bond strength, additional rheological and thermoanalytical analyses are done under nearprocess conditions. The influence of prepreg pre-crosslinking, a function of the mold temperature, is also described by means of additional tests in which specific pre-crosslinking of the prepreg is adjusted by the temperature storage and then functionalized in integrative process combination. The aim of the study is to identify and understand initial process limits for the integrative process combination for a potential process window.
\end{abstract}

Keywords Thermoset injection molding $\cdot$ Thermoset hybrids $\cdot$ Integrative manufacturing $\cdot$ In situ curing

\section{Introduction}

Increasing environmental regulations to reduce $\mathrm{CO}_{2}$ emissions with rising costs for fossil fuels leads to a necessary improvement of resource efficiency in all transport sectors [1]. Air traffic, in particular, is growing rapidly, and the pressure to reduce $\mathrm{CO}_{2}$ emissions is high. The minimum economic lifetime of a commercial aircraft is 20 years of operation. A weight reduction of $1 \mathrm{~kg}$ for an Airbus A340 reduces fuel consumption by $3 \mathrm{t}$ in the calculated 20 years [2]. Assuming the aircraft is operating on the principle of complete combustion, this would correspond to a $\mathrm{CO}_{2}$ reduction of $9.45 \mathrm{t}$ [3]. If this were applied across all aircraft in the Star Alliance fleet, a reduction of 44,100 $\mathrm{t} \mathrm{CO}_{2}$ would be possible in 20 years by reducing the weight of each aircraft by $1 \mathrm{~kg}$ [4]. Fiberreinforced polymer (FRP) composites have excellent weightspecific mechanical properties, making them well suited to reduce aircraft weight by substituting metallic materials [5].

Tim Deringer

tim.deringer@fau.de

1 Institute of Polymer Technology, Friedrich-Alexander University Erlangen-Nuremberg, Erlangen, Germany
The primary structure of the Boeing Dreamliner is, therefore, already $50 \%$ by weight FRP [6]. The majority of these FRP components have a thermoset polymer base. However, thermoset FRPs, and their processing methods, are subject to various restrictions. Widely used processes such as autoclave and resin transfer molding (RTM) have relatively long cycle times, or the prepreg molding process, which is limited to shellshaped components. Thermoset injection molding, on the other hand, offers much greater design freedom and allows FRP production without major design restrictions. However, the fiber length and, thus, the breakdown behavior are significantly lower than with continuous fiber-reinforced components.

According to the limitations of the individual processes, there are attempts to combine the different processes and the properties of the respective materials in the production of FRP to understand additional application areas and weight savings that cannot be served by FRP using conventional processes. Bergmann [7] combines RTM and thermoset injection molding. In RTM, continuous fibers are impregnated with epoxy resin and cured. In an intermediate step, the surface is treated by laser, or the resin is removed, excluding the continuous fiber. The cured continuous fiber-reinforced component is subsequently transferred to an injection mold and injected with a short fiber-reinforced epoxy resin-based molding compound [7]. However, two further process steps and surface 
treatments between them are necessary to produce the hybrid components. In [8], Wufsberg shows investigations on the combination of prepreg compression molding and a carbon fiber sheet molding compound (SMC) pressing in one step and one mold. Prepregs are inserted as a core between sheet molding compound layer into a non-autoclave pressing mold and pressed by the closing movement. Both components are cured together under pressure. Compared to Bergmann, the cycle time is shorter and more efficient, but functionalization by SMC presses offers limited design freedom and lower reproducibility than with injection molding $[7,8]$.

For thermoplastic fiber composites, in-mold-forming is established to produce hybrid components with a molded continuous fiber-reinforced part, and an injection-molded part [9, 10]. A preheated organic sheet is placed in an injection molding machine and formed by the closing movement, followed by overmolding with a short fiber-reinforced thermoplastic. Both components cool and solidify together and are demolded as a hybrid component. However, due to their properties, such as higher temperature stability, chemical resistance, lower creep tendency, and emergency running properties, thermosets are more suitable for aviation than thermoplastics [11]. Moreover, thermosets are at a lower price level than thermoplastics with comparable mechanical and thermal properties, e.g., polyether ether ketone (PEEK). In terms of processing, thermosets have fundamentally different behavior than thermoplastics due to their reaction kinetics.

A new process for manufacturing thermoset hybrid highperformance FRP components is the combination of thermoset injection molding and prepreg molding. A detailed process description is found in "Novel process." The process combines the individual advantages of both processes and materials. Compared to conventional processes, the process chain is shorter as the continuous fiber-reinforced component is formed in one process step, functionalized with a thermosetting molding compound, and both materials are cured together. This results in functionalized continuous fiber-reinforced components with a high degree of design freedom, which have the potential to achieve lower costs than comparable components.

Both the injection molding component and the prepreg are based on thermosetting epoxy resins. The molecule chains, which are short in the initial state, cross-link under the influence of heat to form a macromolecule whose properties depend on the degree of cross-linking. In turn, the degree of cross-linking results from the curing conditions such as curing temperature and curing time [12]. With increasing curing temperatures, the cross-linking rate accelerates. For a theoretical, fully cross-linked structure, all cross-linking partners must be bonded together. In practice, however, it is not possible to achieve a $100 \%$ degree of cross-linking, as not all the crosslinking partners are found [13]. The exothermic chemical reaction releases heat. This is measured as reaction enthalpy and is used as an indicator of the degree of cross-linking/degree of cure [13]. The degree of cure indicates the progress of the curing process. As the degree of cure increases, properties such as toughness [14], strength [15], and the glass transition temperature [16] are influenced.

Sampaio et al. [17] show that for a light-activated resin based on ethoxylated bisphenol-A-dimethacrylate and 2hydroxyethyl methacrylate, the adhesion to a ceramic surface increases with increasing degree of cure. By increasing the degree of cure from 68 to $12 \%$, the adhesive strength increases by about $17 \%$. The same effect on the degree of cure is analyzed in [18] between acrylated epoxidized soybean oil and hemp fibers. For injection molding, Zhao et al. [19] show the influence of pre-crosslinking on weld line strength. Here, increased pre-crosslinking increases the holding pressure effect in the process for the low-filled molding compound used. The improved holding pressure effect improves the weld line strength.

An occurring reaction mechanism between different epoxy resins has been demonstrated for individual epoxy systems on a scientific scale so far. The combination of a bisphenol base and a cyanate ester is analyzed in [16]. Due to the co-reaction between the two resins, a mixed system of both resins with different properties compared to the starting resins is formed at the interface [16]. The new molecular structure of the mixed system cross-links with the pure starting resins and forms an intercross-linked network. A cross-linked mixed network of bisphenol-A-dicyanate and a novolak epoxy resin is investigated by Mathew et al. [20]. The esters react with the epoxy groups to form oxazolidinone, and a new network is created despite the different resin bases of bisphenol-A and novolak. In [21], a reaction between aliphatic epoxy resins and an amine hardener, which is normally used for bisphenol-A epoxy resins, is detected.

The aim of this work is to identify the first process limits for the combination of short fiber-reinforced thermoset molding compounds and a continuous fiber-reinforced thermoset prepreg in an integrative process as a function of mold temperature and curing time.

\section{Experimental procedure}

\subsection{Materials}

For the thermoset injection molding, an epoxy molding compound with a filling degree of 69 wt.- $\%$ of the commercial type Epoxidur EP 3585 T (Raschig GmbH, Germany, Ludwigshafen) is used. Following the manufacturer's specifications, the curing time per millimeter is $20 \mathrm{~s}$ for a minimum mold temperature of $150^{\circ} \mathrm{C}$. For the mold part, a continuous fiber-reinforced pre-impregnated semi-finished product (prepreg) is used. It is a commercial fast-curing prepreg of 
the type 362 GMP (Mitsubishi Rayon, Tokyo, Japan) with an epoxy resin base, new on the market. The reinforcement structure is a woven $2 \times 2$ twill fabric of TR $30 \mathrm{~S} 3 \mathrm{~L}$ carbon fiber with its commercial chemical sizing for epoxy. The chemical composition of the sizing is not known. The basis weight of the fabric (FAW) is $240 \mathrm{~g} / \mathrm{m}^{2}$ with an epoxy resin content of $40 \%$ by weight. According to the manufacturer's specifications, the fastest curing condition during compression molding is given with a minimum curing time of $5 \mathrm{~min}$ at a mold temperature of $140^{\circ} \mathrm{C}$. The cured thickness per ply is 0.27 $\mathrm{mm}$.

\subsection{Noval process}

The combination of prepreg compression molding and thermoset injection molding in one mold is shown in Fig. 1. The uncured prepreg is placed in an isothermally heated mold at the beginning of the process. Immediately following, the mold closing movement takes place, leading to the consolidation of the prepreg. Once the mold is completely closed, the injection gate is applied to the mold and the injection process is initiated. During injection, the uncured molding compound contacts the surface of the uncured prepreg. Both components, prepreg and molding compound, then cure together under molding pressure. At the end of the process, the hybrid component made of the molding compound and prepreg, including sprue, is demolded. The sprue is cut manually with a standard side cutter.

The used mold technology is installed in a KM 80 CX SP 180 thermoset injection molding machine (KrausMaffei, Munich, Germany). The injection unit is temperaturecontrolled at $60^{\circ} \mathrm{C}$ in the feed zone and $80^{\circ} \mathrm{C}$ in the injection zone. The injection speed is $5 \mathrm{~mm} / \mathrm{s}$, and the holding pressure is $1 \mathrm{MPa}$. The parameters are selected according to the manufacturer's recommendations and preliminary tests. The changeover point is controlled at a cavity pressure of $10 \mathrm{bar}$. The mold temperatures are varied between $130^{\circ} \mathrm{C}, 140^{\circ} \mathrm{C}$, $150^{\circ} \mathrm{C}, 160^{\circ} \mathrm{C}$, and $170^{\circ} \mathrm{C}$ with curing times between 90 and $240 \mathrm{~s}$.

In addition to investigating the effects of temperature and time, the enflux of the prepreg pre-crosslinking is investigated for some specimens. The defined pre-crosslinking of the prereg is achieved by temperature storage in a K759 oven (Heraeus, Hanau, Germany) at $120^{\circ} \mathrm{C}$ at varied curing times. After temperature storage, the samples are immediately cooled in liquid nitrogen and stored in a freezer at $-20^{\circ} \mathrm{C}$ to prevent post-curing. Quality control for compliance with the precrosslinking/curing levels is carried out by means of random
Fig. 1 Process sequence for the integrative combination of prepreg compression molding and thermoset injection molding in one mold

\section{Handling}

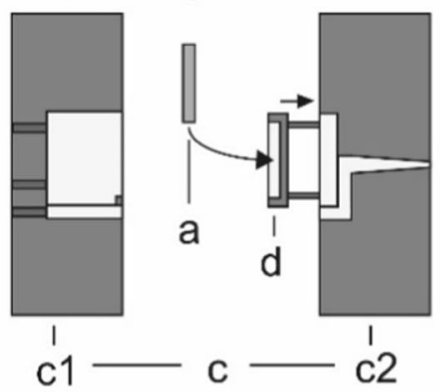

\section{Demolding}
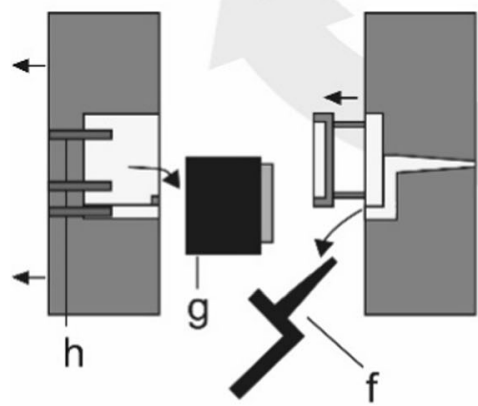
a: Prepreg
b: Molding compound
c: Injection Mold
c1: Moveable mold half
c2: Fixed mold half

\section{Functionalization}

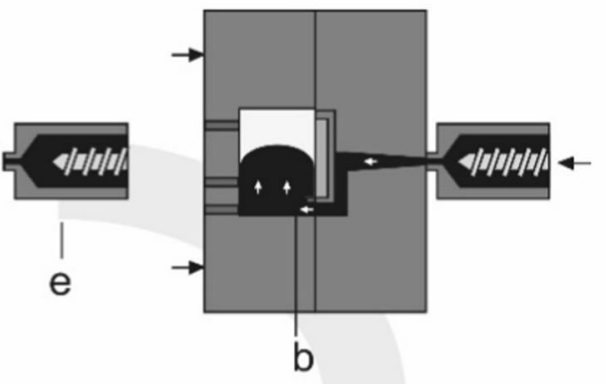

3. Joint Curing

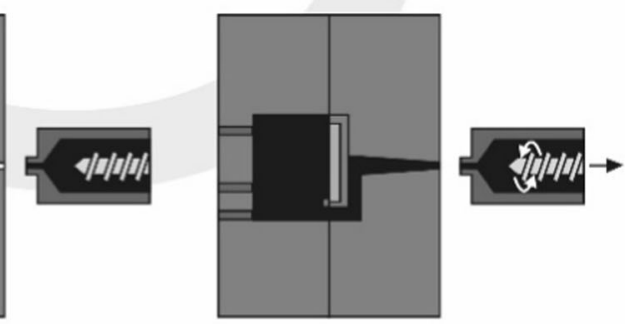

d: Spring-loaded cavity

e: Injection molding unit

f: Spure

g: Hybrid component

h: Ejector 
DSC measurements for each setting. The maximum standard deviation in the determination of the pre-crosslinking is $5 \%$.

\subsection{Test specimen}

The analyses in this publication are based on the rib specimen shown in Fig. 2a-c. The ribbed structure corresponds to a stump with a radius of $0.25 \mathrm{~mm}$ in the area of the interface between the molding compound and the prepreg. The radius serves to reduce possible notch effects in the pull-off test. The layer structures for the prepreg consist of 7 layers. The alignment of the warp direction of the continuous fiber reinforcement to the rib cavity is $0 \% / 90$ for all layers. The single layers of the prepreg are stacked and cold-pressed with 0.07 $\mathrm{MPa}$. The joining surface between the molding compound and prepreg is $100 \mathrm{~mm}^{2}$. Pull-off tests are carried out with a selfdeveloped test device in a universal testing machine type Zwick Roell 1474. The test setup is seen in Fig. 2 d. Compared to a shear test specimen for single lap joints, as in ASTM D1002 used for adhesives, the single rib specimen allows a perpendicular load on the joining surface. All specimens are tested at a test speed of $0.5 \mathrm{~mm} / \mathrm{min}$ under the same conditions according to DIN EN ISO 291. The adjusted gap dimension is for all tests $4.5 \mathrm{~mm}$.

\subsection{Degree of cure}

The enthalpy of the produced specimens is determined by differential scanning calorimetry (DSC) and compared to the enthalpy of the respective starting material. The degree of cure is calculated from this enthalpy. In addition, the heat-up rate is
$10 \mathrm{~K} / \mathrm{min}$ in a temperature range from 0 to $250^{\circ} \mathrm{C}$. Implementation and procedure are carried out according to DIN EN ISO 11357. The device used is of type Q 1000 TMDSC (TA-Instruments, New Castle, USA).

To investigate the pre-crosslinking of the prepreg as a function of the mold temperature, fresh prepregs are inserted into the rib mold and the process is initiated. At the time of injection, the process is stopped and the state of the prepreg is immediately frozen in liquid nitrogen. The degree of cure is then determined as described above.

For the possible linking of DSC and rotational viscometry, additional dynamic measurements are carried out on the prepreg at a heating rate of $5 \mathrm{~K} / \mathrm{min}$. With the exception of the heating rate, the analyses are carried out analogously to the previously described tests.

\subsection{Viscometry}

The viscosity is measured in accordance with DIN 53019 (2008) using an AR 2000 rotational viscometer (TAInstruments, New Castle, USA). However, the measuring procedure is carried out in a different manner. At the beginning of the measurement, the test chamber is preheated isothermally to the target temperature. The specimen is then placed in the testing chamber immediately starting the measurement. The specimen thickness is based on the respective cross-section thickness in the component. The measuring system used is a plate-plate structure with a diameter of $20 \mathrm{~mm}$. The frequency is $1 \mathrm{~Hz}$ with a strain of $0.1 \%$. The choice of the test temperatures is analogous to the varied mold temperatures. a)
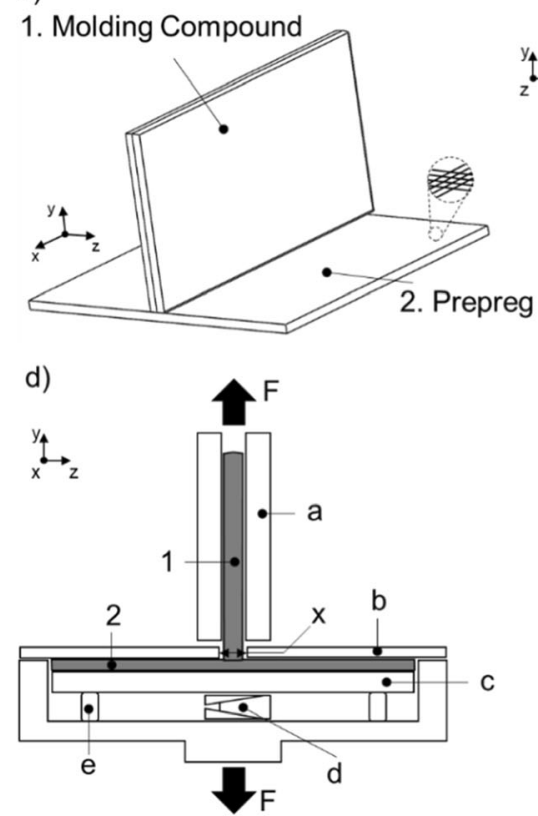

b)

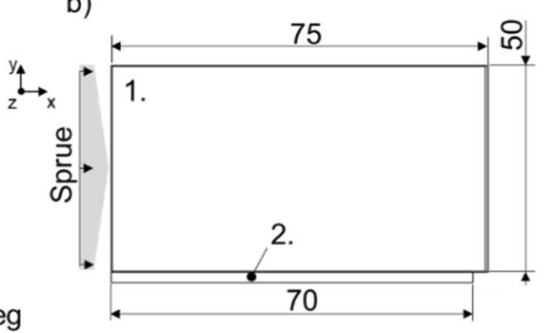

c)

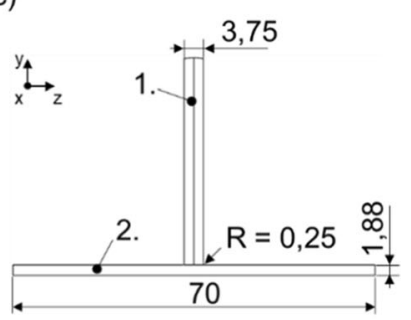

Single rib speciemen

1. Molding compound

2. Prepreg

a) Clamping device

b) Upper clamping plate

c) Lower clamping plate

d) Counter clamp

e) Spring pins

x) Adjusted gap dimension

Fig. 2 Dimension of the rib specimen $(\mathbf{a}-\mathbf{c})$ and the schematic representation of the rib pull-off test 
To analyze the gel point of the prepreg, additional dynamic Rotvis measurements are carried out with a heating rate of 5 $\mathrm{K} / \mathrm{min}$. Deformation, loading frequency, and specimen sizes are analogous to the previous measurements.

\subsection{Microscopy}

The interface of the rib specimen is analyzed using a VK-X laser scanning microscope (LSM) (Keyence, Ōsaka, Japan). In each case, the analyses are performed through the specimen center in cross-section. For this purpose, the single rib specimen is tailored with a water-cooled saw in the middle part. Afterward, the cut surface is sanded down and polished. Furthermore, fracture images are investigated by a scanning electron microscope of the type Zeiss Ultra Plus (Carls Zeiss AG, Oberkochen, Germany). For additional imaging in the nanometer range, an ultra-high-resolution BrightBeam ${ }^{\mathrm{TM}}$ SEM optics was used (TESCAN Orsay Holdings, Brno, Czech Republic)

\subsection{Mass pressure}

The value of the melt pressure is measured data, which is output via the measurement of the hydraulic pressure of the thermoset injection molding machine KM 80 CX SP 180 (KrausMaffei, Munich, Germany). This describes the pressure that occurs in the screw antechamber during the injection process/screw stroke. The measured value describes the pressure that is present after overcoming the initial pressure maximum and during mold filling before the cavity pressure increases.

\section{Results}

\subsection{Mold temperature and pre-crosslinking of the prepreg}

For the novel integrative process of combining the molding compound and prepreg in thermoset injection molding, Fig. 3 illustrates the resulting bond strength between the components and the degree of cure of the materials as a function of mold temperature. With an increasing mold temperature, the level of bond strength rises up to $160^{\circ} \mathrm{C}$. The increase in the bond strength up to $160^{\circ} \mathrm{C}$ is explained by the increase in the degree of cure, and the resulting improvement in the mechanical properties of the individual materials. The maximum bond strength for both material combinations is reached at a mold temperature of $160^{\circ} \mathrm{C}$. At $170^{\circ} \mathrm{C}$, a drop in the bond strength is observed irrespective of the course of curing. Thermogravimetric analyses, not shown in this publication for reasons of space, rule out a possible chain degradation in

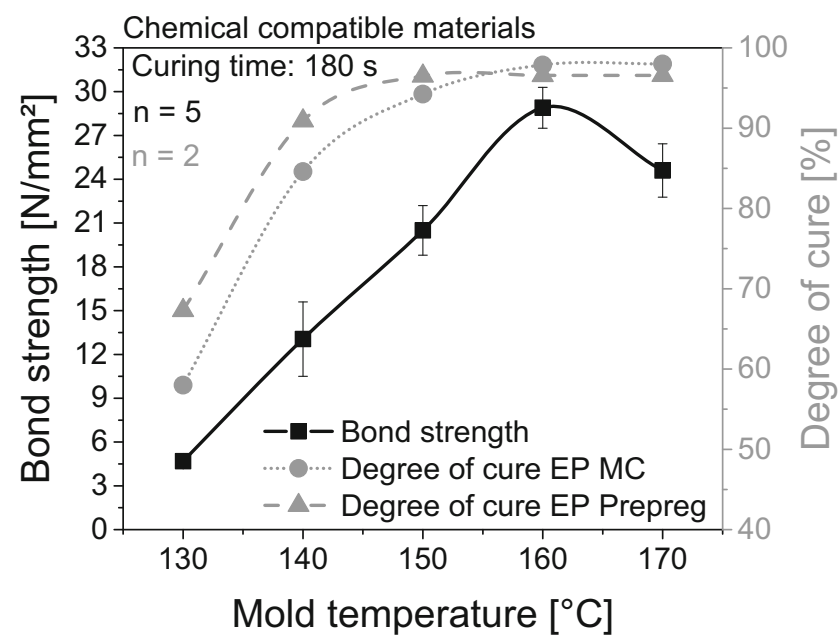

Fig. 3 Resultant bond strength as a function of mold temperature

one of the components at $170^{\circ} \mathrm{C}$ as the cause of the drop in bond strength.

The corresponding fracture surfaces resulting from mechanical failure of the interface in the rib pull-off test are shown in Fig. 4. For the specimen produced at a mold temperature of $130^{\circ} \mathrm{C}$, no molding material residue is evident in the fracture surface. In addition, the microscope image shows exposed continuous fibers without resin or molding material residues on the fiber surface. This indicates low adhesion, which likely results from the low curing levels. The fracture of the resin system between the fibers resembles a brittle fracture with a smooth surface. With increasing mold temperatures from 130 to $160^{\circ} \mathrm{C}$, molding compound residues increase quantitatively on the prepreg surfaces at the fracture surfaces. While for $140^{\circ} \mathrm{C}$, molding compound residues are mainly seen at the surface nodes of the rovings; at $150^{\circ} \mathrm{C}$, the molding compound also adheres in isolated cases to the roving surface away from nodes of the fabric. For a mold temperature of $160^{\circ} \mathrm{C}$, on the other hand, large-area molding compound residues result on the prepreg surface. The corresponding microscope images show molding material residues on the continuous fibers in the temperature range from 140 to $160^{\circ} \mathrm{C}$. Accordingly, good fiber-matrix adhesion is also assumed. In addition, the microscope images suggest a penetration of the molding compound, including fillers, into the fiber interstices of the prepreg. The fracture surface in the resin system appears comparatively ductile. By increasing the mold temperature to $170^{\circ} \mathrm{C}$, the fracture pattern changes fundamentally. Compared to preceding mold temperatures, a significantly lower quantity of molding material residues is seen on the prepreg surface at $170^{\circ} \mathrm{C}$. The fracture pattern in the resin system changes fundamentally as the mold temperature increases. The microscope images also differ significantly from the previous ones. Compared to $140^{\circ} \mathrm{C}$ to $160^{\circ} \mathrm{C}$, for $170^{\circ} \mathrm{C}$ residues of molding compound and fillers are seldom visible on or between the continuous fibers. 

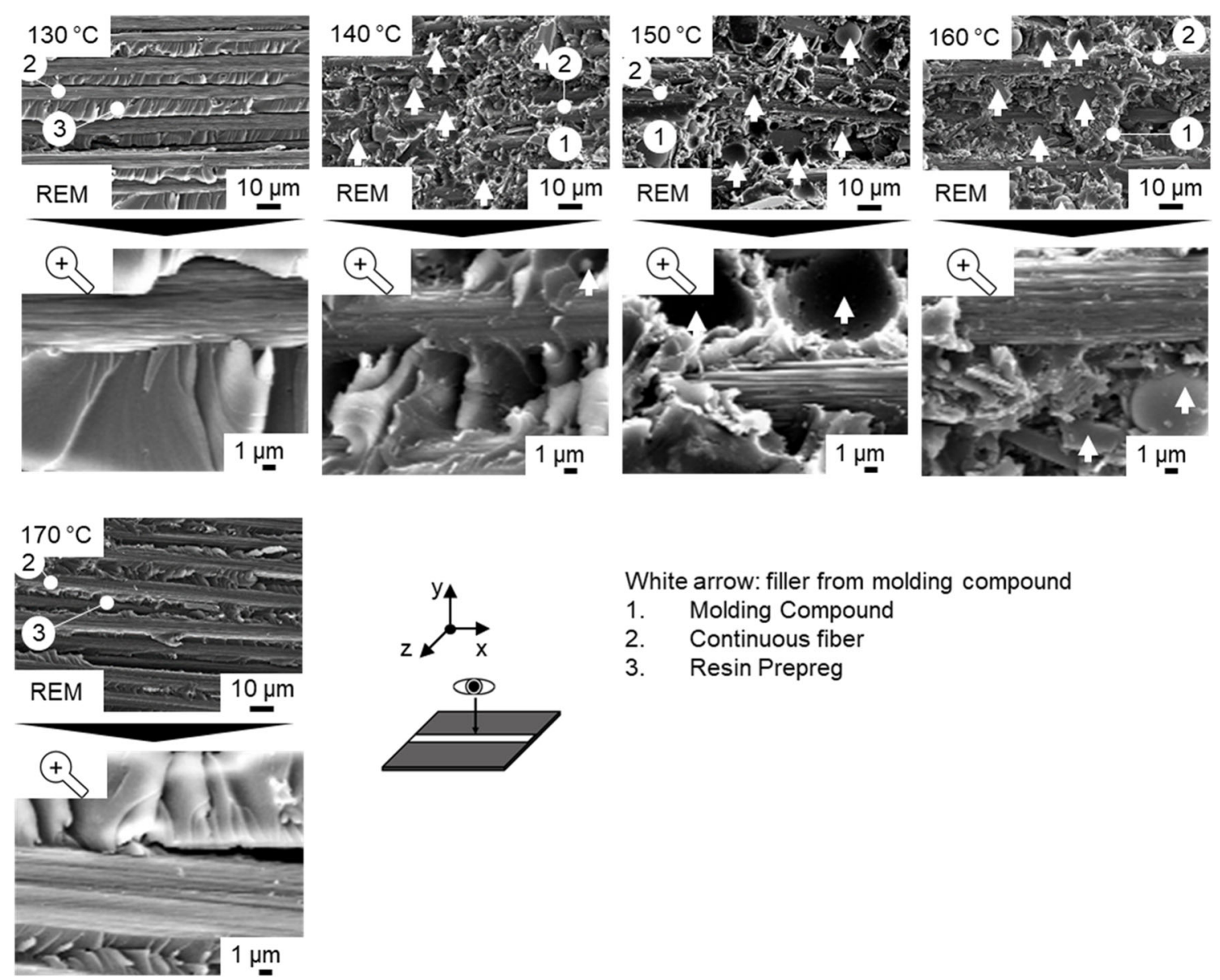

White arrow: filler from molding compound

1. Molding Compound

2. Continuous fiber

3. Resin Prepreg

Fig. 4 Fracture surface of the prepreg as a function of the mold temperature

The explanation of the behavior is possible with the aid of the microscope images in the component cross-section in the area of the interface in Fig. 5. At $130^{\circ} \mathrm{C}$, it is hard to localize fillers in the molding compound since microscopic air inclusions have a considerable effect on image quality. For $140^{\circ} \mathrm{C}$ and above, there are no air inclusions and the fillers from the molding compound and prepreg are clearly visible. The detected fillers of the molding compound are marked in

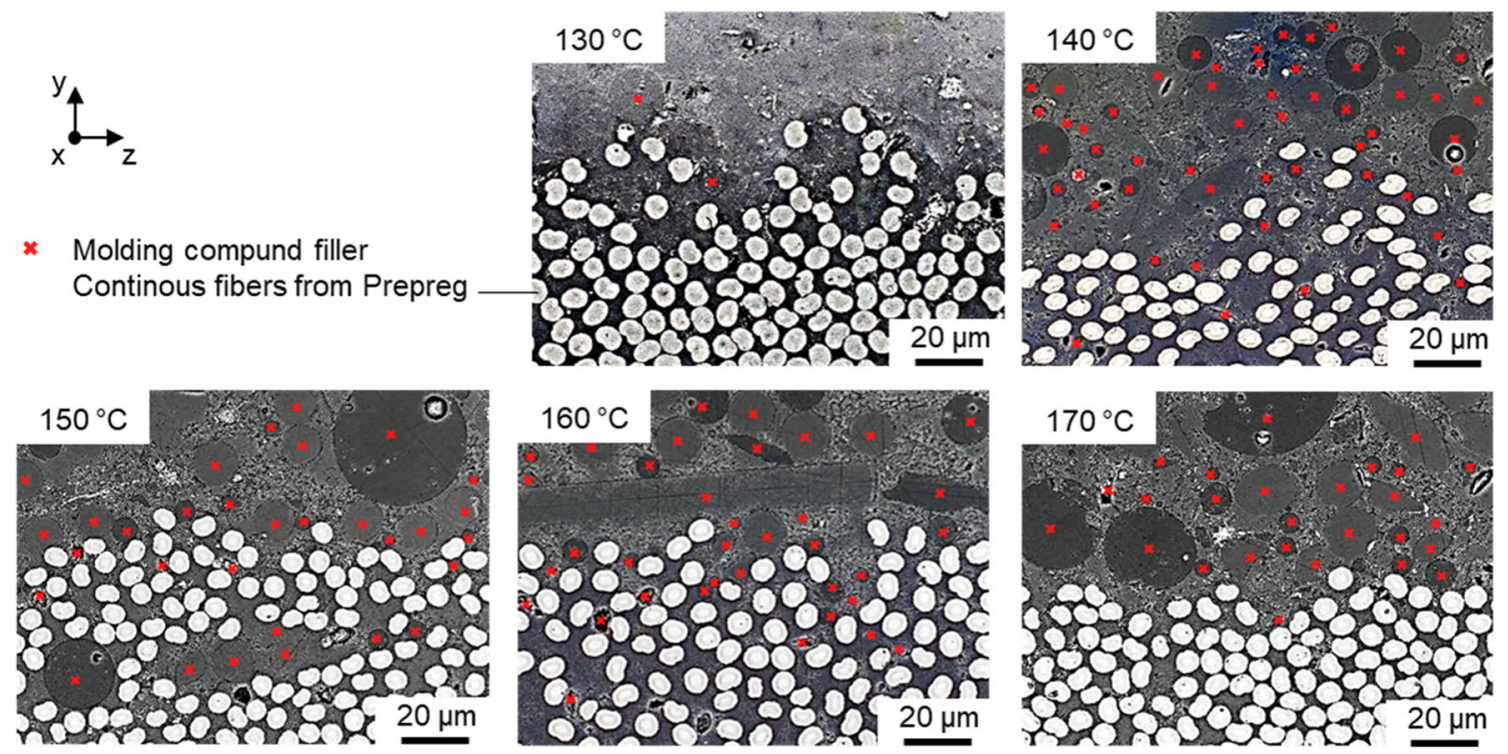

Fig. 5 Exemplary laser scanning images in the interface of the rib specimen as a function of the mold temperature 
red in Fig. 5. There are no clear boundary layers between the molding compound and prepreg. Fillers, such as glass fibers, glass beads, or minerals of the molding compound, are identified not only in the injection-molded area but also in the prepreg area between the continuous fibers. Accordingly, it is assumed that during injection, the molding compound, including the resin system and fillers, penetrates into the interstices of the continuous fibers. Also, in the cured state, undercuts exist between the two materials and contribute to the formation of mechanical adhesion. For mold temperatures above $170^{\circ} \mathrm{C}$, this penetration of the molding compound into the interstices of the continuous fibers is not demonstrated. This lack of mechanical anchorage is responsible for the decrease in bond strength in Fig. 3, and the change in fracture behavior in Fig. 4.

The reason for the different penetration behavior of the molding compound may be the change in viscosity depending on the mold temperature. The viscosity curves of the materials combined resulting from integrative processing are plotted accordingly under near-process measuring conditions as a function of mold temperature in Fig. 6 on the left. The thermoset molding compound is shown in gray, and the prepreg is in black. Since the focus for the molding compound is on the first measuring point, because the molding compound hits the prepreg immediately after contact with the hot mold wall during the process, the viscosity minima resulting at the beginning are shown as measuring points. Within the standard deviation, the viscosity of the molding compound in the temperature range from 140 to $170^{\circ} \mathrm{C}$ is approximately at a low level in a comparable range. For $130^{\circ} \mathrm{C}$, however, the viscosity is strikingly higher than at the previously mentioned mold temperatures. This significantly higher viscosity at $130^{\circ} \mathrm{C}$ can be the cause of poor penetration of the molding compound into the cover layer of the prepreg or the high pore content in the molding compound, which is detected in Fig. 5. The drop in bond strength at $170^{\circ} \mathrm{C}$, on the other hand, is not attributable to the molding compound. However, an indication of the cause is seen in the analysis of the viscosity curves of the prepreg. Since the prepreg is in contact with the mold wall for about $10 \mathrm{~s}$ before the time of functionalization, this time is also considered. While up to a mold temperature of $160^{\circ} \mathrm{C}$, the viscosity of the prepreg remains unchanged at a low level within the standard deviation; at $170^{\circ} \mathrm{C}$, it shows twice the value after $10 \mathrm{~s}$. This also correlates with the microscope images of the cross-sections. The viscosity increase of the prepreg, thus, leads to a poorer penetration behavior of the molding compound. This causal viscosity increase results from the change in the respective pre-crosslinking of the prepreg as a function of the mold temperature, seen in Fig. 6 on the right. By increasing mold temperature, the pre-crosslinking of the prepreg rises because the prepreg is in contact with the mold wall for about $10 \mathrm{~s}$ before injection. While the precrosslinking for mold temperatures up to $160^{\circ} \mathrm{C}$ amounts to a maximum of $12 \%$, for $170^{\circ} \mathrm{C}$, this is already approximately 3 times as high. The maximum values of pre-crosslinking at $170^{\circ} \mathrm{C}$ are up to $40 \%$.

To determine the relationship between prepreg precrosslinking, prepreg viscosity, and the resulting bond strength, the prepregs were subjected to additional predetermined temperature storage and functionalized. Defined cross-linking states of the prepreg are set by varying the storage times. The variation of the pre-crosslinking of the prepreg including the resulting bond strength between the molding compound and prepreg is shown in Fig. 7 on the left. Figure 7 on the right shows the link between the degree of cure and viscosity and the gel point of the prepreg. Increasing the pre-crosslinking reduces the reactants available for functionalization of the prepreg. For a pre-crosslinking of 0 to $20 \%$, no influence from a change in the quantity of reactants is seen within the standard deviation. A viscosity change due to the increasing crosslinking also rarely occurs in this range. With increasing pre-crosslinking, the bond strength drops,
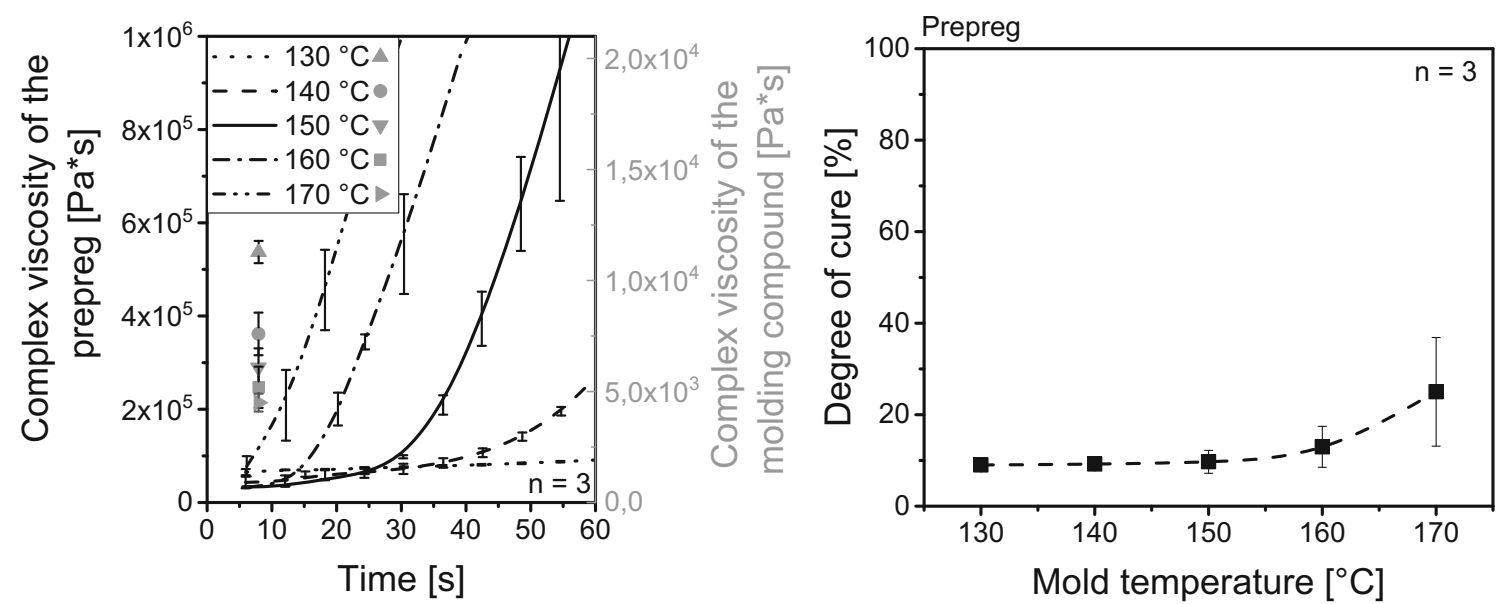

Fig. 6 Viscosity of the prepreg and viscosity minimum of the molding compound (left) and pre-crosslinking of the prepreg at the time of gating as a function of mold temperature (right) 

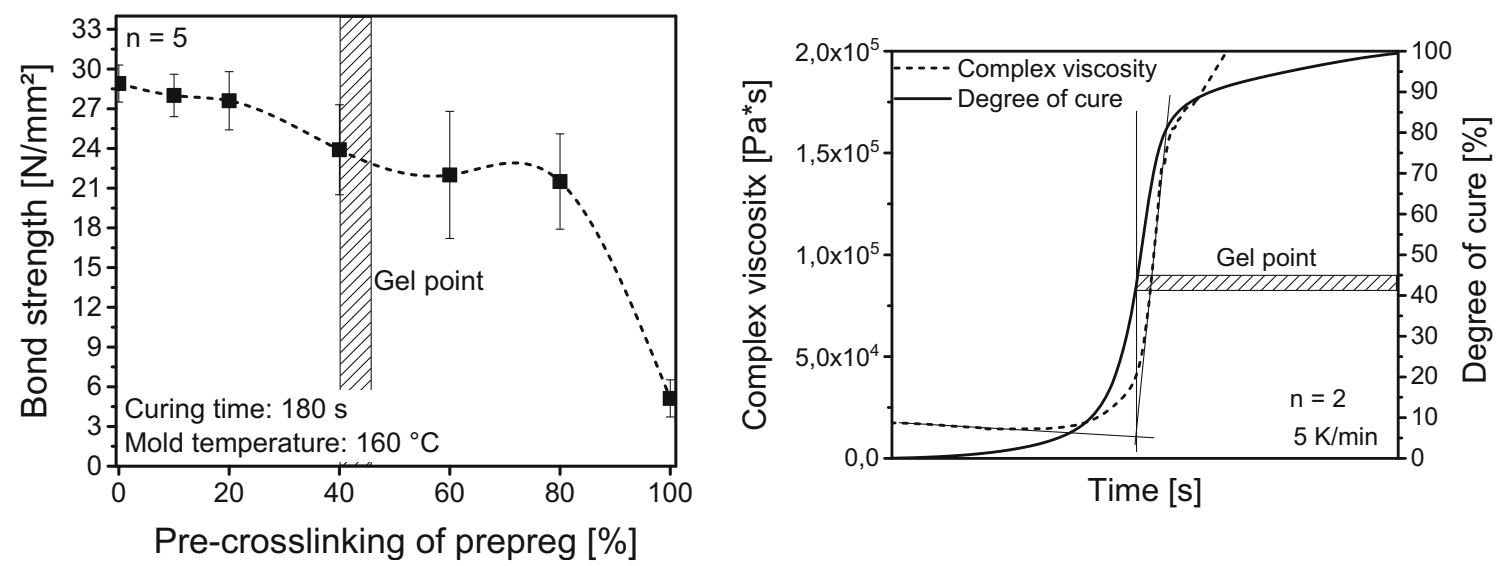

Fig. 7 Bond strength as a function of pre-crosslinking of the prepreg (left) and determination of the gel point (right)

specifically as the gel point is crossed. Once the gel point range is crossed, the bond strength settles at a level of approximately $80 \%$ of the initial strength. A change in the number of reaction partners due to the degree of pre-crosslinking likely has no influence on the later resulting bond strength up to $80 \%$. Up to a degree of pre-crosslinking of $80 \%$, reductions in the bond strength mainly result from the change in viscosity. Only in the pre-crosslinking range from 80 to $100 \%$ is the influence of the reduced number of reaction partners dominant, leading to an almost abrupt drop in the bond strength. The drop in bond strength while crossing the gel point exhibits the same behavior as increasing the mold temperature from 160 to $170^{\circ} \mathrm{C}$ and the associated rise in pre-crosslinking of the prepreg.

Figure 8 displays the analysis of the interfaces by means of LSM at $500 \times$ magnification as a function of the precrosslinking. For a pre-crosslinking of the prepreg of 0 $20 \%$, no difference in the formation of the interface is detected. The fillers of the molding compound penetrate into the interstices of the continuous fibers, and undercuts between both materials are understood. The penetration depth of the fillers is about $50 \mu \mathrm{m}$. With a degree of pre-crosslinking of $40 \%$, only isolated local undercuts are recognized, but the maximum penetration depth of the fillers, approximately $20 \mu \mathrm{m}$, is reduced compared to the previously shown degrees of pre-crosslinking below 20\%. Above a degree of pre-crosslinking of $60 \%$, no filler penetration into the interstices of the continuous fibers is possible. A degree of pre-crosslinking of $80 \%$ also shows that penetration of fillers into the interstices of the continuous fibers of the prepreg is no longer possible. Furthermore, the continuous fibers are exclusively surrounded by a dark gray area which is identified as pure prerpeg resin. Accordingly, from a pre-crosslinking level of $80 \%$, there is no longer direct contact between the molding compound and the continuous fibers of the prepreg.

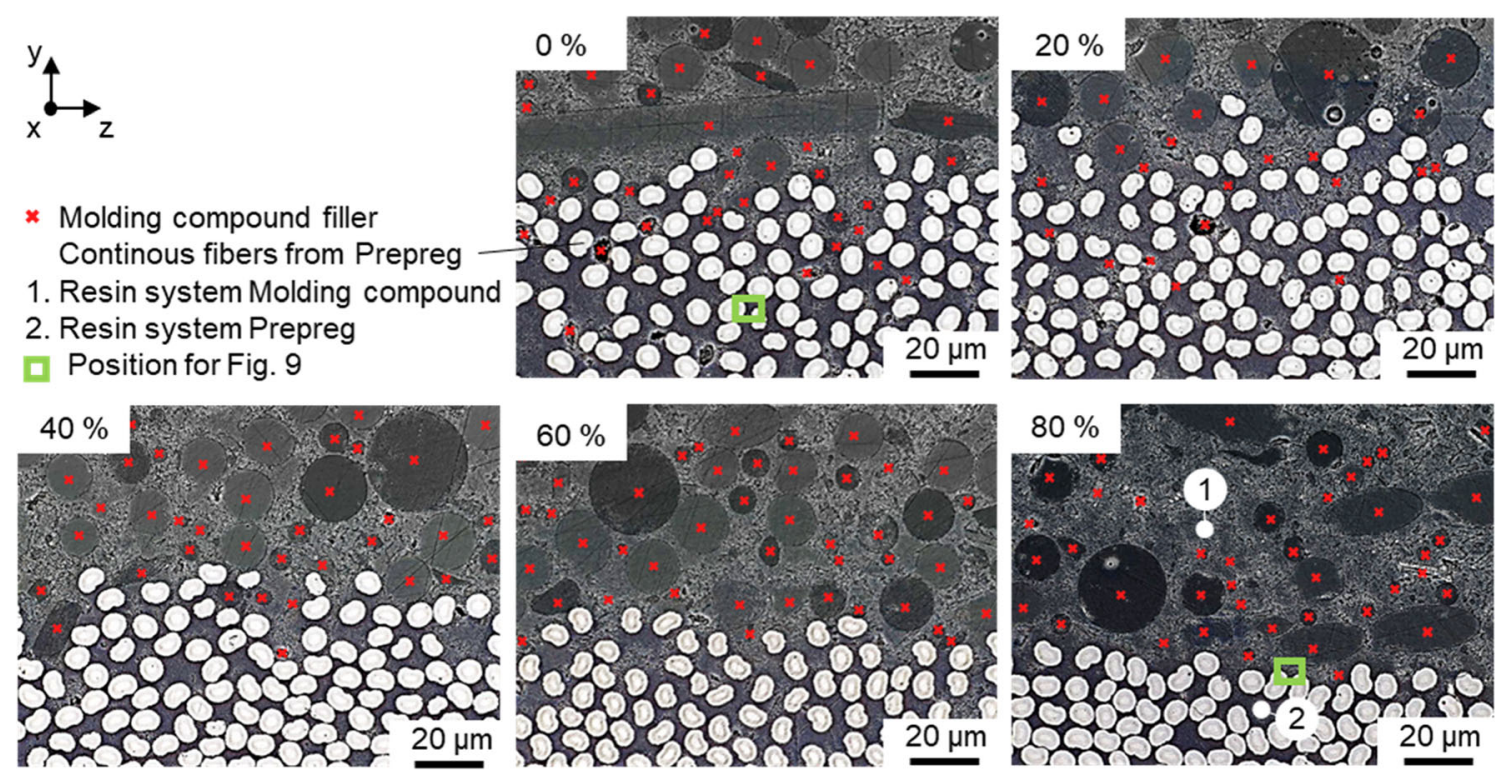

Fig. 8 Penetration behavior of the molding compound into the prepreg as a function of pre-crosslinking 
A comparison of Fig. 5 and Fig. 8 also shows, with respect to the microscopic interfaces formed, a clear transferability of the specimens from those manufactured at a mold temperature of $170^{\circ} \mathrm{C}$ and with a pre-crosslinking of more than $40 \%$ (above the gel point). The decrease of the bond strength is, thus, primarily due to the insufficient formation of undercuts caused by the excessively high viscosity of the prepreg resin. Moreover, at $60 \%$ and $80 \%$ pre-crosslinking, no penetration of the fillers into the prepreg is possible; nevertheless, the bond strengths remain the same. Accordingly, it is assumed that the formation of chemical adhesion is still possible at very high pre-crosslinking levels.

Supplementary studies in Fig. 9 show the interface between the pure resin systems in the nanometer range. Looking at Fig. 9, taking into account the positions of the images in Fig. 8, for $0 \%$ pre-crosslinking in the immediate vicinity of the infiltrated fillers, the resin of the molding compound can also be seen in white. At a pre-crosslinking of $80 \%$, however, it can only be found on the prepreg surface. This supports the previously established thesis that the infiltrated fillers are a direct indicator of the penetration behavior of the molding compound into the prepreg. A comparison of the images at the different degrees of pre-crosslinking also shows that the contrast between the resin systems at $0 \%$ is markedly lower than at $80 \%$. This could indicate that at $0 \%$ pre-crosslinking mixing effects or possibly also diffusion between the resin systems takes place, which, on the other hand, is significantly lower at $80 \%$. Detailed investigations on the boundary effects between the resin systems will be published in a subsequent paper.

\subsection{Curing time}

In addition to the mold temperature, the curing time is one of the dominant processing parameters in the processing of thermosets. With a view to the economic efficiency of a process, the aim is to keep it as short as possible. Accordingly, the dependence of the resulting bond strength of integratively produced components on the curing time at a defined mold temperature, in the case under consideration $160^{\circ} \mathrm{C}$, is shown in Fig. 10. With an increasing curing time, the degree of cure of both combined materials increases. The bond strength rises

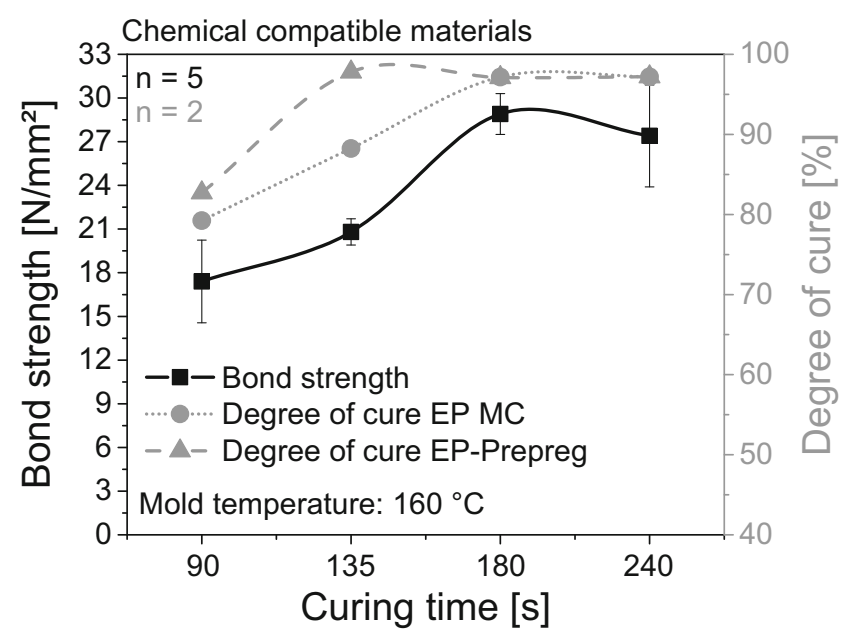

Fig. 10 Residual bond strength as a function of curing time

analogously to the degree of cure and reaches its maximum for both material combinations at a curing time of $180 \mathrm{~s}$. With a further extension of the curing time, no change in the bond strength is detectable within the standard deviation. However, for a curing time of $240 \mathrm{~s}$, a significant increase in the standard deviation is seen, which indicates a decrease in process stability. In contrast to the variation of the mold temperature, there is no differentiated influence on the pre-crosslinking of the prepreg due to the extension of the curing time.

However, increasing the curing time has a direct influence on the total cycle time, thus on the residence time of the molding compound in the aggregate. During the entire residence time, the molding compound is subject to thermal stress initiated by the aggregate temperature. This is also indicated in an isothermal rotational viscometry under comparable conditions in Fig. 11 on the left. At $80^{\circ} \mathrm{C}$, the viscosity of the molding compound starts to increase after $200 \mathrm{~s}$. The viscosity increase is primarily due to an increasing pre-crosslinking of the molding compound, which increases by approximately 5\% compared to a curing time of 180 to $240 \mathrm{~s}$. However, an influence on the bond strength cannot be evaluated in the investigated range within the standard deviation. This increase in precrosslinking is likely too small to have a direct influence on the formation of the network in the interface.

Hence, it is deduced for the investigated variation range that as soon as complete curing is achieved, the bond strength, theoretically, remains at one level regardless of the curing

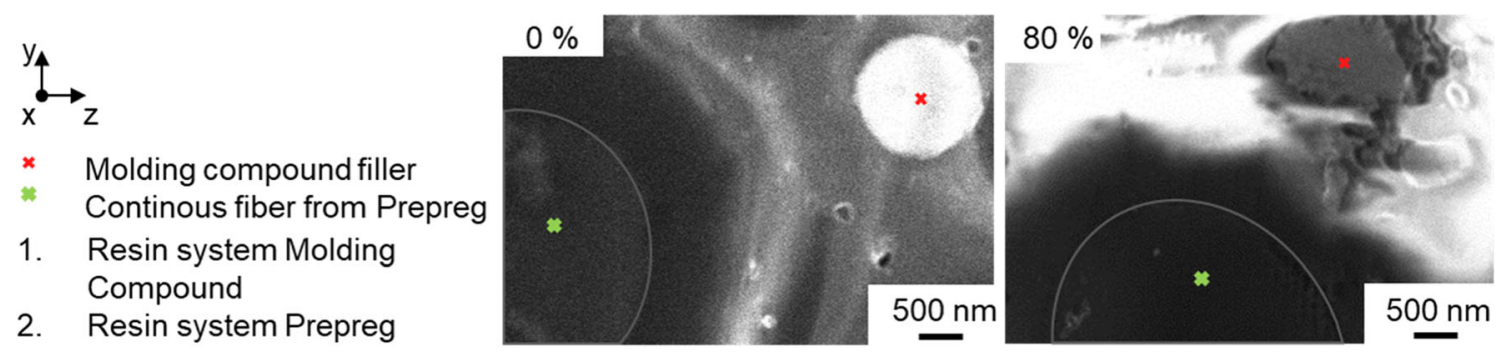

Fig. 9 Interface of the different resin systems for $0 \%$ and $80 \%$ pre-crosslinking, the imaging position can be seen in Fig. 8 

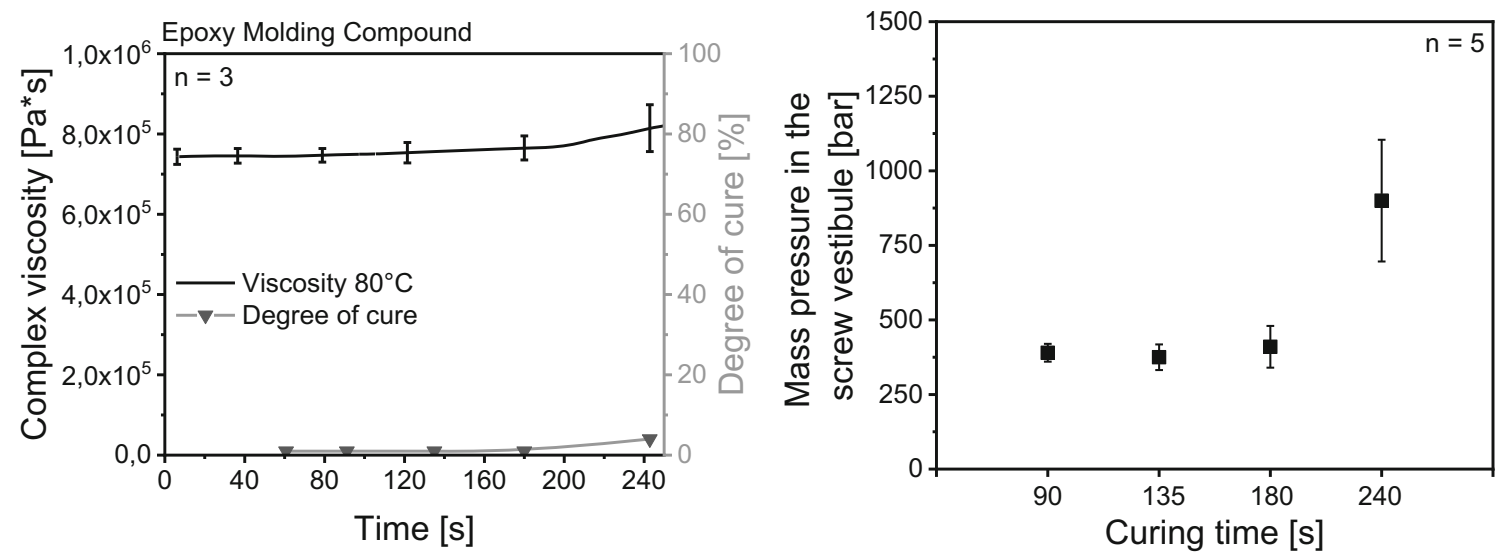

Fig. 11 Isothermal rotvis based on the aggregate temperature for the EP molding compound (left) and mass pressure in the aggregate as a function of the residence time/curing time (right)

time, as no further cross-linking points are generated between the two materials, and the mechanical material properties remain unchanged. Nevertheless, a significant increase in the standard deviation for a curing time of $240 \mathrm{~s}$ is also evident, which indicates a decrease in process stability with continued dwell time. A change in viscosity under mold temperature as a function of the dwell time is not detected, but there is a clear influence on the melt pressure in the screw antechamber illustrated in Fig. 11 on the right. While there is no change in the required melt pressure within the standard deviation for curing times of the prepreg up to $180 \mathrm{~s}$, it is many times higher for $240 \mathrm{~s}$ than for the shorter dwell times. Furthermore, a significant increase in the standard deviation is detectable in the resulting melt pressure. The significantly higher fluctuation in the melt cushion could, thus, also affect the injection process and its control accuracy.

\section{Conclusion}

In the present work, the dominant process variables, mold temperature and curing time, and their effects on the resulting bond strength were investigated for a novel integrative process of combining molding compounds and prepregs in thermoset injection molding. Raising the mold temperature at a constant cure time leads to an increase in the bond strength at the interface due to an enhancement of the degree of cure and the associated number of crosslinking points. The resulting fracture behavior changed from a purely adhesive fracture to a mixed fracture with increasing cohesive fractions. The maximum bond strength was measured at $160^{\circ} \mathrm{C}$, but above this temperature, the bond strength dropped again. The fracture surface here indicated a primarily adhesive failure behavior. The driving cause was identified as pre-crosslinking due to the temperature increase and the related viscosity change of the prepreg. At $170^{\circ} \mathrm{C}$, the resin system of the prepreg already exceeded a degree of pre-crosslinking prior to its functionalization by the molding compound, indicating the approach of the gel point transition. As the gel point was approached and exceeded, a clear decrease in the penetration behavior of the molding compound into the fiber interstices of the continuous fiber reinforcement of the prepreg was evident at the interface. The mechanical adhesion associated with the penetration behavior of the molding compound into the prepreg was accordingly greatly reduced. In contrast, the influence of pre-crosslinking on the reduction of the chemical adhesion was only measurable at pre-crosslinking degrees of more than $80 \%$. At constant mold temperatures and varied curing times, the degree of cure achieved by the two components was primarily decisive for the level of adhesion. With curing times above $240 \mathrm{~s}$, and correspondingly long residence times of the molding compound in the aggregate, an increase in viscosity was observed in the aggregate, which leads to possible process fluctuations. The measured viscosity increase was attributed to the increasing pre-crosslinking.

Acknowledgements Authors thank the support of the German Federal Ministry of Economic Affairs and Energy according to a decision of the German Federal Parliament (funding no. 20W1503D), the research partner Schmidt WFT GmbH, C.K. Siebenwurst GmbH \& Co. KG, Gubesch Group, and the German Aerospace Center (DLR) and Raschig GmbH. Furthermore, we thank the chair FAPS for providing the ultra-highresolution BrightBeam ${ }^{\mathrm{TM}}$ SEM optics from TESCAN.

Availability of data and materials Not applicable.

Author contribution Tim Deringer conceived and performed the experiments. Dietmar Drummer helped with the data analysis and revision of the paper.

Funding Open Access funding enabled and organized by Projekt DEAL. There is no research grant involved in this article writing, and the author's sponsorship is already mentioned in the acknowledgments section

\section{Declarations}

Ethics approval Not applicable. 
Consent to participate Not applicable.

\section{Consent for publication Not applicable.}

Competing interests The authors declare no competing interests.

Open Access This article is licensed under a Creative Commons Attribution 4.0 International License, which permits use, sharing, adaptation, distribution and reproduction in any medium or format, as long as you give appropriate credit to the original author(s) and the source, provide a link to the Creative Commons licence, and indicate if changes were made. The images or other third party material in this article are included in the article's Creative Commons licence, unless indicated otherwise in a credit line to the material. If material is not included in the article's Creative Commons licence and your intended use is not permitted by statutory regulation or exceeds the permitted use, you will need to obtain permission directly from the copyright holder. To view a copy of this licence, visit http://creativecommons.org/licenses/by/4.0/.

\section{References}

1. Santos G (2017) Road transport and CO2 emissions: what are the challenges?. Transport Policy 59:71-74

2. Grimme W (2008) Measuring the long-term sustainability of air transport - an assessment of the global airline fleet and its $\mathrm{CO}_{2}$ emissions up to the year. Air Transport and Airport Research :1-12

3. Rypdal K (2018) Aircraft emissions. Good practice guidance and uncertainty management in national greenhouse gas inventories 1 : 93-102

4. N N (2020) Available from: https://www.staralliance.com/de/ home\#member-airlines

5. Lin Z-M (2013) Making aviation green. Advances in Manufacturing 1:42-49

6. Hale J (2006) Boeing 787 from the ground up. Aero Boeing 4: 17-23

7. Bergmann N (2017) Funktionsintegrierte duroplastische Leichtbauteile durch Hinterspritzen von endlosfaserverstärkten Duroplast-Strukturen mittels Duroplast-Spritzgießen. in Fachtagung Duroplast-Spritzgießen-Vernetzte Forschung für die Produktion der Zukunft, Aachen

8. Wulfsberg J P, Herrmann A S, Ziegmann G (2014) Combination of carbon fibre sheet moulding compound and prepreg compression moulding in aerospace industry. Procedia Engineering 81: 1601-1607

9. Müller T et al (2009) In-mold forming as a novel injection molding process to manufacture high-performance hybrid composites, in
SAMPE Europe, 30th. International Jubilee Conference and Forum, Paris

10. Kazan H, Zheng T, Farahani S, Pilla S (2019) Degree of cure, mechanical properties, and morphology of carbon fiber/epoxy-PP hybrids manufactured by a novel single shot method. materialsdoday 19:441-449

11. Brosius D (2015) Thermosets vs. thermoplastics: is the battle over? Composite World :141-193

12. Endruweit A (2003) Thesis: Investigation of the influence of local inhomogeneities in the textile permeability on the resin flow in liquid composites moulding processes, in Swiss Federal Institute of Technology Zurich: 1-294

13. Boehm M (2015) Reaction kinetics and cure monitoring of highly reactive epoxy resins for carbon fiber reinforced plastics. Thesis, LMU Munich

14. Marks M, Snelgrove RV (2009) Effect of conversion on the structure-property relationships of amine-cured epoxy thermosets. ACS Appl Mater Interfaces 1:921-926

15. Deringer T, Gröschel C, Drummer D (2016) Influence of mold temperature and process time on the degree of cure of poxy-based materials for thermoset injection molding and prepreg compression molding. J Polym Eng 38:73-81

16. Krumweide G, Akau R (1996) Applications of high thermally conductive $\mathrm{K} 1100 \mathrm{X} /$ resin systems to spacecraft structure and equipment. AIP Conf Proc 361: 883-888

17. Sampaioa PC, de Castro KP, Ribeiroa C, Hilgerta L, Rodrigues Pereira P (2017) Comparative bonding ability to dentin of a universal adhesive system and monomer conversion as functions of extended light curing times and storage. J Mech Behav Biomed Mater 75:41-49

18. Liu W, Fei M, Ban Y, Qiu R, Qiu J (2018) Concurrent improvements in crosslinking degree and interfacial adhesion of hemp fi bers reinforced acrylated epoxidized soybean oil composites. Compos Sci Technol 107:2411-2502

19. Zhao Y, Mattner T, Drummer D (2019) Investigation of the effects of pre-cross-linked thermoset molding compounds on weld line strength in injection molding. Int J Adv Manuf Technol 105: 1723-1733

20. Mathew D, Reghunadhan NCP, Ninan KN (1999) Bisphenol A dicyanate-novolac epoxy blend: cure characteristics, physical and mechanical properties, and application in composites. J Appl Polym Sci 74:1675-1685

21. Pham H Q, Marks M J (2005) Epoxy resins. Ullmann's Encyclopedia of Industrial Chemistry 13:156-238

Publisher's note Springer Nature remains neutral with regard to jurisdictional claims in published maps and institutional affiliations. 